\title{
A RECORDING MICROMETER FOR GEOMETRICAL ROCK ANALYSIS
}

\author{
S. J. SHAND \\ Victoria College, Stellenbosch, South Africa
}

The quantitative estimation of minerals in rock sections is generally recommended as a valuable exercise, but in practice it is far too seldom performed. The reason is that the recognized methods of estimation are very tedious, while the results, when obtained, have not hitherto been put to any systematic use in the classification of rocks. The usual methods are of two kinds, viz., (I) separations, either gravitational or magnetic, the separated portions being weighed directly; and (2) geometrical methods, involving measurement either of areas or of diameters, and subsequent calculation of percentage volumes and percentage weights.

Of estimations of the latter class, the following variants are known to me:

I. The method of Delesse: The surface of the rock is polished and oiled, and the outlines of the grains are traced on transparent paper, the areas corresponding to different minerals being distinctively colored. The paper is then pasted upon tinfoil, and cut up along the boundaries of the grains. The fragments having been grouped according to color, the paper is removed and the tinfoil weighed. The weights so found are proportional to the areas traced upon the paper, hence also to the volumes occupied by the different kinds of grains, provided that the rock is uniform throughout. To get the proportions of the various minerals by weight, each volume must be multiplied by the specific gravity of the corresponding mineral.

2. The outlines of the grains may be traced upon squared paper, and the areas obtained by counting the number of squares occupied by each mineral, all broken squares being reckoned as half-squares. 
3. Methods I and 2 can be applied to microscopic sections by the aid of a camera lucida attached to the microscope. An ordinary photographic camera can also be used, the outlines of the grains being sketched from the enlarged image on the focusing screen.

4. If a dark room is at hand, it is sometimes preferable to photograph a rock section instead of sketching it. The print can be examined either by weighing or by means of squared paper.

5. A squared ocular micrometer, by means of which the areas of the grains in a section can be measured directly under the microscope, was tried by Rosiwal. It was found to be less advantageous than the following method, viz.:

6. Rosiwal's linear traversing method:I If the work be executed with care and under all necessary precautions, this is the simplest and perhaps for that reason the most accurate of all geometrical methods of rock analysis. The measurement of areas is replaced by the measurement of diameters along a selected line or lines. Either a microscopic section or the smooth face of a hand-specimen of the rock may be employed, according to whether the rock is of fine or coarse grain. In the latter case, a graduated rule or tape is required; in the former, an ocular micrometer. Any kind of micrometer will do, but the estimation is facilitated by the use of certain special types, such as the "planimeter ocular" of Hirschwald. ${ }^{2}$ Subject to certain conditions, the number representing the sum of the diameters of all grains of one kind is proportional to the volume of the mineral concerned.

So far as tediousness is concerned, all these methods are more or less on the same level; the measurements are very wearisome and take a long time to perform. Generally speaking, one would expect weighing to be a more exact process than the use of squared paper, but then the weighing must be preceded by sketching and cutting out, and appreciable errors may creep in during these manipulations; furthermore, one cannot be sure that the material weighed, be it tinfoil, cardboard, or paper, is everywhere of the same thickness. On the other hand, the counting of innumerable

' Rosiwal, "Über geometrische Gesteinsanalysen," Verhandlungen der k.k. geolog. Reichsanstalt, Wien (1898), No. 5 .

${ }^{2}$ J. Hirschwald, Centralblatt für Min., Geol., Pal. (1904), No. 20. 
tiny squares is a most aggravating business, and the fewer the squares, the greater the probable error in the result. On the whole, the advantage seems to be with the Rosiwal method, as being both simpler and more direct than the others. The practical disadvantages of the method are two: First, the making of very many minute measurements by the aid of the scarcely visible scratches on the eyepiece micrometer puts a severe strain upon the eyesight, as well as upon the patience, of the observer. After an hour or two of such work I have sometimes been nearly blind. Secondly, the writing down and adding up of some hundreds or even thousands of measurements is itself a most tedious operation.

To obviate these serious disadvantages of the Rosiwal method, I have devised a stage micrometer which both makes the measurements and performs the addition of them; it consequently effects a great reduction in the time needed for the estimation, and incidentally reduces the strain on the eyes to a minimum. The first instrument was made from my drawings by Mr. T. A. Linton, at the South African College, Cape Town, and I have pleasure in expressing my appreciation of his excellent workmanship.

The design is very simple, and will easily be followed with the aid of the drawings (Figs. I, 2, 3). The rock section, mounted as usual on a glass slide, fits into a rectangular brass sledge $A$, which is movable to right or left of the observer, within another sledge $B$, the movement being accomplished, and its amount recorded, by the micrometer screw $L$. Sledge $B$ moves in the same manner and direction within sledge $C$, the movement being performed and recorded by the micrometer screw $R$. Sledge $C$ has no transverse movement; it carries two runners on its under surface which travel in grooves on the sides of the rectangular stage of the microscope; the only movement of this sledge is to and from the observer and is effected simply by hand.

Suppose it is required to estimate the volume of augite in a dolerite. The section is put in place and adjusted till one edge of it appears against the point of intersection of the cross-wires in the eyepiece of the microscope. The readings of screws $R$ and $L$ are written down. Then screw $R$ is turned continuously until a grain of augite is brought up to the cross (i.e., the point of inter- 


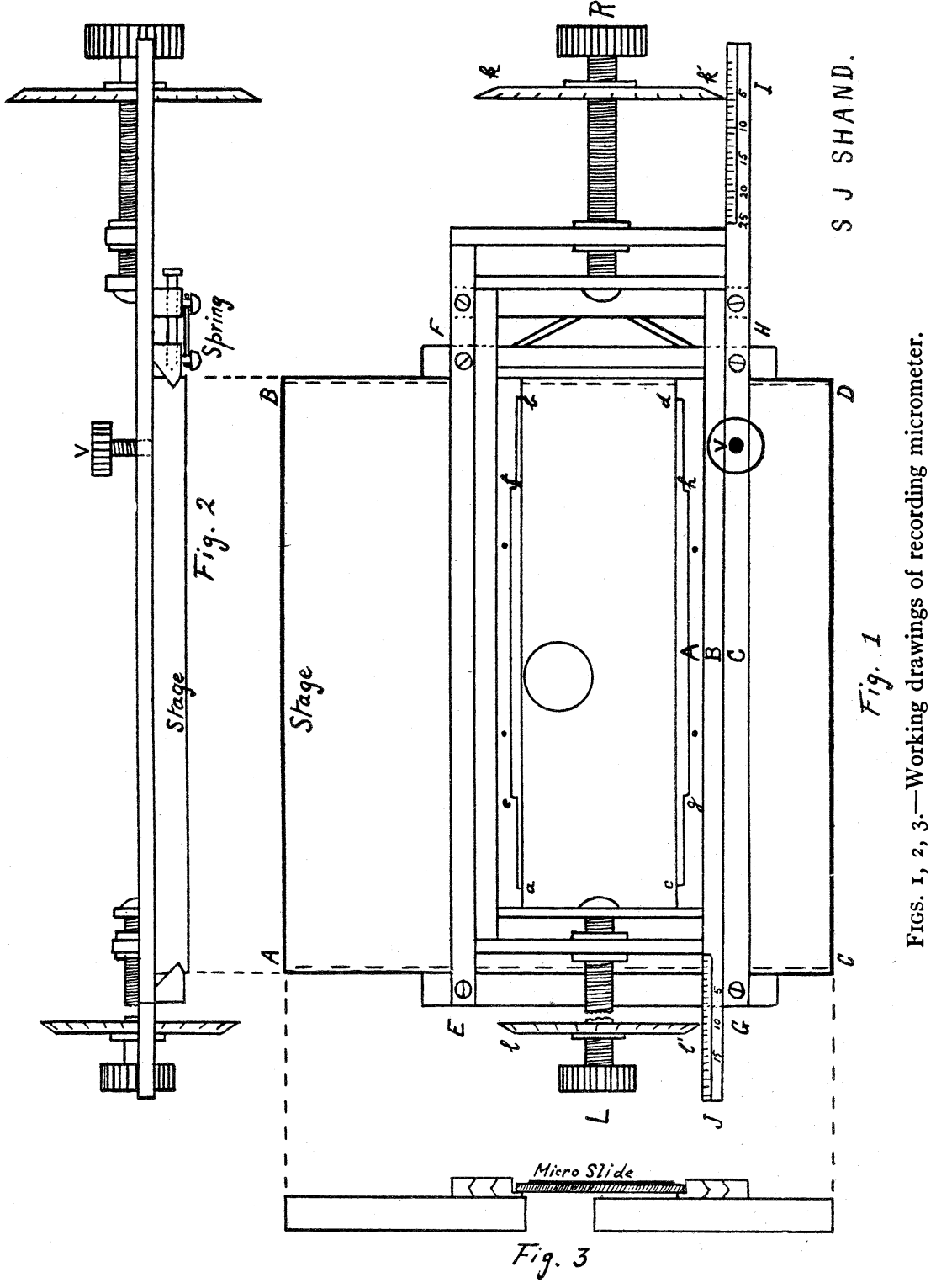


section of the cross-wires); screw $L$ is now turned until the grain travels past and its other margin lies exactly beneath the cross; then screw $R$ is turned till the next augite grain comes into position; then screw $L$ till the grain has passed, and so on. When the traverse has been completed, which with a section of ordinary size may take from one to three minutes, the readings of the micrometer sctews are again noted and written down below the former readings. It is obvious that the difference between the two readings of screw $L$ gives the sum of the diameters of all the augite grains which were intersected during the traverse, while the difference for screw $R$ gives the sum for all other minerals in the rock. Without stopping to make these subtractions, however, sledge $C$ is pushed forward into a new position and a second traverse is made in the return direction; at its completion the micrometers are again read and the readings jotted down beneath the previous ones. Sledge $C$ is again pushed forward, and another traverse made, and so on until the number of traverses is considered sufficient. One may now proceed to the subtraction of the successive readings, and the calculation of the percentage of augite, which is obviously

$\frac{\text { sum of successive differences of } L}{\text { sum of successive differences of } L+\text { sum of successive differences of } R} \times 1 \infty$.

The most expeditious manner of recording the readings is to write them down in parallel, vertical columns in the middle of the page; then, when all the measurements have been made, the differences of $L$ are quickly filled in to the left and the differences of $R$ to the right, as in Table I, on p. 399, which is part of an actual estimation.

It will be seen that by this method only two numbers have to be recorded for each traverse after the first, while by any other method some twenty or more may be necessary.

It may be advisable at this stage to recall the conditions which, as Rosiwal has pointed out, must be observed if the linear traversing method is to give reliable results.

I. The length measured must be at least one hundred times the average grain of the rock. (With the additional facility afforded by the recording micrometer, it would involve little extra labor 
to increase this minimum to two hundred or even four hundred, and I strongly advocate the increase.)

2. Two measured lines should be at least the width of a grain apart.

3. When the constituents are fine-grained and uniformly distributed, measurement of a single section may be sufficient; if coarse-grained, several sections may be necessary in order to satisfy conditions $I$ and 2.

TABLE I

\begin{tabular}{c|c|c|c}
\hline Diff. & \multicolumn{1}{c|}{$L$} & \multicolumn{1}{c|}{$R$} & Diff. \\
\hline 6.43 & 3.82 & 8.05 & 16.60 \\
9.18 & 10.25 & 24.65 & $\mathrm{I} 3.40$ \\
5.86 & 1.07 & $\mathrm{II} .25$ & 17.45 \\
6.93 & 6.93 & 28.70 & $\mathrm{I} 76.25$ \\
7.62 & 0.00 & 12.45 & 15.23 \\
\hline 36.02 & 7.62 & 27.68 & \\
\hline Percentage $=$ & $\frac{36.02}{36.02+78.93} \times 100=31.3$ & 78.93 \\
\hline
\end{tabular}

Total distance traversed, $57.5 \mathrm{~mm}$.; time taken for measurements and calculation, 12 minutes.

4. In the case of a rock with parallel structure it is necessary, and in most cases it is desirable, to take measurements both along and across the section.

5. The most accurate method is to measure all the minerals present at the same time, rather than one at a time, although the latter is the quicker way. (This recommendation applies to the use of an ordinary micrometer; it is of course inapplicable to the recording micrometer.)

6. In the case of coarse-grained rocks it is often quickest to measure a polished face macroscopically, using sections only for minor or microscopic constituents.

Rosiwal's practice is to draw fine lines on the cover-glass with ink, and then measure along these lines. This is not necessary 
if the stage of the microscope happens to be ruled with cross-lines, as is often the case.

The method having been described, it remains to add some details about the construction of the instrument. In making the first model, we took the micrometer screws out of two small spherometers; these had just the right length (about $\mathrm{I} \frac{1}{2}$ inches) and pitch

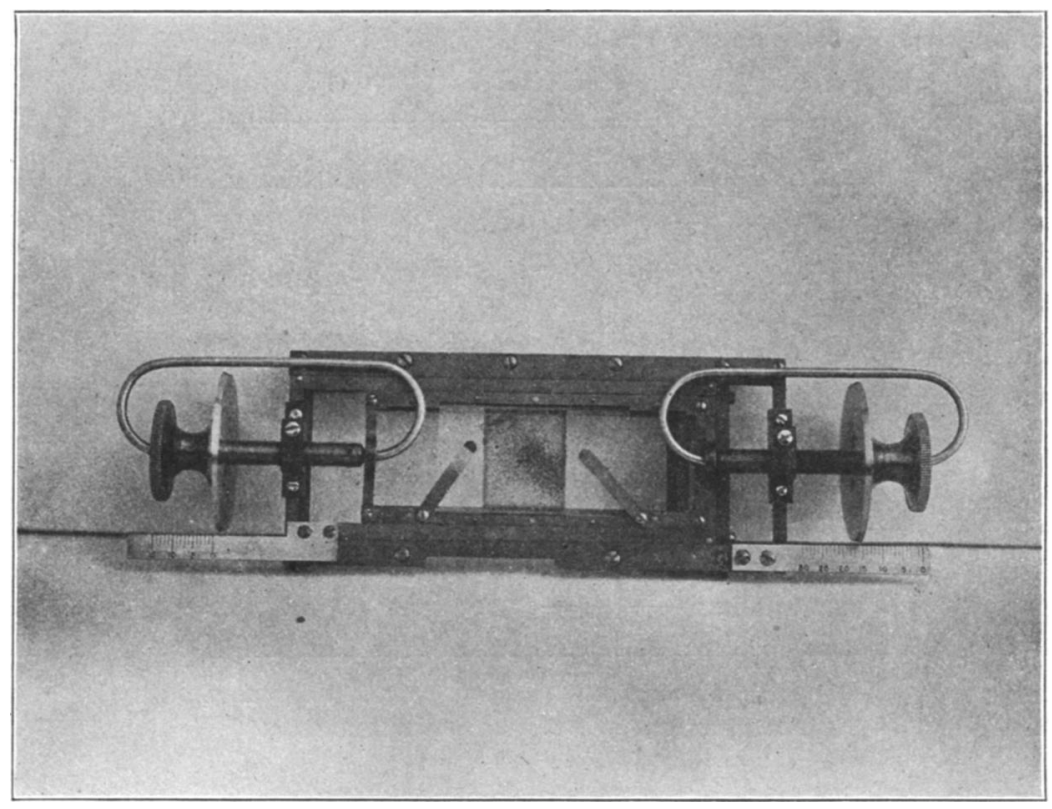

FIG. 4.-Photograph of original micrometer

(0.5 mm.) and were used almost without modification. The numbers on the graduated disk run in the correct direction for screw $L$, but must be reversed for screw $R$. These screws proved, on trial, to be unsatisfactory, having been taken from a cheap type of spherometer (the only kind obtainable in South Africa at the time), and better ones have since been substituted for them by Messrs. Swift \& Son, London. It is of course essential that the screws shall be machine-cut with the highest degree of accuracy; that the axis shall be perfectly straight; and the graduated disks truly plane and set exactly at right angles to the axis. The precise pitch of the 
screw does not matter at all, but a pitch of about one-half to one millimeter is convenient. The scales which record the movement of the screws are of course graduated to correspond to the pitch, and the divisions on both scales are numbered from right to left.

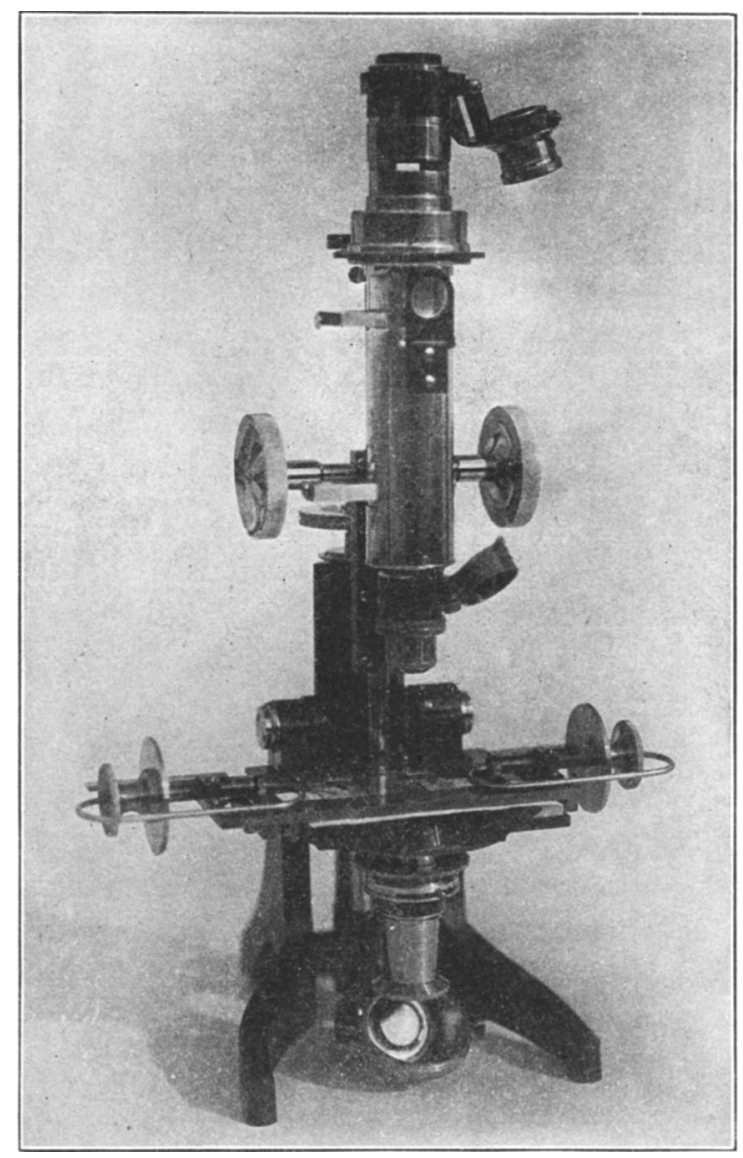

FIG. 5.-The micrometer in position on the stage of an "Allan Dick" petrological microscope (Messrs. Swift \& Son, London).

The ends of the screws may be rigidly attached to the sledges $A$ and $B$, but can be more simply secured by means of backlash springs. The innermost sledge $A$ carries two slots, one of them ( $a b c d)$ made to take the standard English size of slide $(75 \times 25 \mathrm{~mm}$.), the other 
(efgh) to take German slides $(48 \times 28 \mathrm{~mm}$.). Two small spring clips (not shown in the figure) serve to prevent any slight movement of the glass. In order to allow of measurements being made in two perpendicular directions across a rock section, four short pins are inserted in the sides of sledge $A$; these make it possible to fix a German-sized slide in cross position upon the micrometer, but the English slides are too long to permit this.

The attachment of the outermost sledge $C$ to the stage of the microscope is effected by means of runners with beveled edges which fit into grooves in the sides of the stage. One runner is fixed directly to the under surface of the sledge, the other is attached by a simple wire spring to a fixed cross-bar on the under surface of the sledge. This simple arrangement could be replaced, if desired, by a mechanical movement; in any case it would be an advantage to have an additional screw ( $V$, Figs. I, 2) by means of which the instrument could be clamped to the stage in any desired position. My instrument was made to fit the stage of an "Allan Dick" microscope (Swift \& Son), but it is obviously adaptable to any microscope with a rectangular stage. It could even be adapted to a circular stage by means of a rectangular plate clamped temporarily on top of the stage.

The instrument, as actually made for me, differs in some minor points from the drawings. For instance, the micrometer screws are not rigidly connected to the sledges $A$ and $B$, as the drawing suggests, but are attached by simple backlash springs which can be seen in the photographs (Figs. 4, 5). The dimensions of the side- and end-pieces of the sledges were slightly increased for the sake of greater strength. The figures relating to these parts are as follows:

Length of sledge $A, 85 \mathrm{~mm}$.

Width of sledge $A$ (including bevel), $37 \mathrm{~mm}$.

Travel of sledge $A, 16 \mathrm{~mm}$. (this might be increased).

Length of sledge $B$, 108 $\mathrm{mm}$. (this might be increased).

Width of sledge (including bevel), $45 \mathrm{~mm}$.

Travel of sledge $B, 35 \mathrm{~mm}$.

Length of sledge $C$, I $27 \mathrm{~mm}$.

Width of sledge $C, 54 \mathrm{~mm}$. (might be reduced to $5_{2}$ ).

Thickness of material throughout, $3.5 \mathrm{~mm}$. 
It would be well to allow a greater travel to sledge $A$ by slightly increasing the length of sledge $B$-say to I $2 \mathrm{~mm}$.

A well-finished instrument of this kind could not be made for much less than $£_{5}$, hence it is not likely to become part of every petrologist's equipment; but in view of the saving of time and eyesight which it effects the initial outlay is inconsiderable, and the gain to descriptive petrography, if it should succeed in popularizing the geometrical analysis of rocks, would be very great.

The instrument has been examined by Messrs. J. Swift \& Son, London, who have all the information necessary for executing copies of it.

\section{EXPRESSION OF THE "COLOR RATIO" OF A ROCK}

It has always appeared to me to be a matter of great importance in rock descriptions to state the proportion of light to dark minerals accurately. The terms "leucocratic" and "melanocratic" have proved extremely useful in giving a rough indication of this proportion (which I am in the habit of calling the "color ratio" of the rock), but something more is urgently required. Of course the fundamental point of difference between the light and the dark minerals does not lie in their color, but in their specific gravity, to which, however, the color affords a convenient index, inasmuch as all minerals of gravity less than 2.8 are leucocratic (predominantly light-colored) and those of higher gravity are melanocratic (predominantly dark-colored). It is becoming more and more apparent that differences of specific gravity must be reckoned among the chief causes of magmatic differentiation, and for this reason, as well as for its purely descriptive value, the color ratio must receive quantitative recognition in the future.

With the micrometer described above, it is possible to measure the color ratio of a fine-grained rock with a high degree of accuracy in a period of ten to thirty minutes, according to circumstances. Having ascertained the ratio, the next question is how best to express it, and the way which does least violence to our accepted, illogical system of nomenclature is to resort to a system of prefixes. 
The following ratio and the corresponding prefixes are simple and expressive:

Light minerals more than 97 per cent $\quad l_{10}$ or $\mathrm{L}$

\begin{tabular}{|c|c|c|c|c|c|c|c|}
\hline " & “ & 6 & “ & 90 & “ & $\mathrm{l}_{9}$ & \\
\hline " & “ & " & “ & 80 & “ & $1_{8}$ & or $l$ \\
\hline " & “ & “ & “ & 70 & ، & $\mathrm{I}_{7}$ & \\
\hline " & “ & “ & “ & 60 & “ & $l_{6}$ & or \\
\hline " & “ & " & " & 50 & “ & $\mathrm{l}_{5}$ & \\
\hline Dark & “ & “ & “ & 50 & “ & $\mathrm{m}_{5}$ & \\
\hline “ & " & “ & " & 60 & “ & $\mathrm{m}_{6}$ & \\
\hline " & “ & " & " & 70 & “ & $\mathrm{m}_{7}$ & or \\
\hline " & “ & “ & " & 80 & “ & $\mathrm{m}_{8}$ & \\
\hline “ & " & “ & “ & 90 & “ & $\mathrm{m}_{9}$ & \\
\hline " & “ & “ & “ & 97 & “ & $\mathrm{m}_{\mathrm{IO}}$ & or $\mathrm{M}$ \\
\hline
\end{tabular}

Examples: $L=$ granite (alaskite); $\mathrm{l}_{8}=$ syenite; $\mathrm{lm}=$ dolerite; $\mathrm{m}=$ syenite (shonkinite); $\mathrm{m}_{\mathrm{r} 0}=$ pyroxenite, etc. 